\title{
An Inquiry Study on Teachers' Beliefs and Knowledge of Critical Literacy Pedagogy in Indonesia Context
}

\author{
Raden Aulia Utami Hidayat \\ English Education Department \\ Universitas Pendidikan Indonesia \\ Bandung, Indonesia \\ auliautamihidayat@upi.edu
}

\begin{abstract}
In Indonesia, alternative approaches to language and literature teaching that involve critical literacy tend to be regarded as something new. Teachers who want to apply critical literacy, mostly have limited knowledge or experience of what critical literacy is and how to apply it in their classrooms. This study involved fifteen English teachers in primary schools, secondary schools, and universities in Garut, West Java province, Indonesia, who were surveyed related to their belief and knowledge of critical literacy. The results of an open-ended questionnaire followed by an interview revealed that, although these teachers have been teaching English for about one to sixteen years at various levels and schools, some of them showed a lack of knowledge about critical literacy as a methodological approach to teaching English since they have not been able to distinguish between critical literacy and critical thinking. However, all teachers have a strong belief that critical literacy is important to be applied in teaching and learning practices in order to improve students' ability to understand text. In addition, the study also provides English teachers' expectation in how they can develop a critical literacy- oriented classrooms.
\end{abstract}

Keywords: critical literacy, English as a Foreign Language (EFL), teachers' belief, teachers' knowledge

\section{INTRODUCTION}

Today's education force students to interact with a continual stream of information from the various modes of texts as the impacts of globalization. In addition, the literacy movement is currently being promoted by the government to increase literacy rates in Indonesia. Those phenomena demand the EFL teachers to provide students with the importance of being critical in perceiving the information (Coffey, 2010; Lee, 2011; Lewison, Flint \& Van Sluys, 2002). The term critical literacy concerns the connection between language and social phenomenon (Coffey, 2010; Emilia, 2010; Gustine, 2013). Further, it facilitates students to be critically literate and endorses them to be the part of society who actively participates in a real society by interrogating equality, justice, and social justice within the texts (Wood, Soares \& Watson, 2006). Responding to this, students' critical literacy awareness has to be promoted, including their ability to read and construct critical ideas. In line with this, Alwasilah (2001) stated that to promote students' critical social awareness, education should be applied as a medium to minimize social problems.

However, before promoting the importance of applying critical literacy to students, it is better to know the extent of the teachers' beliefs and knowledge of the critical literacy itself. In line with this, Gustine (2018) found that the majority of teachers still confused with what critical literacy is and how to create and a critical classroom. Whereas, the fact is in conducting a critical-oriented class, the starting point is the teacher should become critically literate to open space for students to be critical (McDaniel, 2006; McLaughlin \& Allen, 2002; Riley, 2015). Moreover, most of critical literacy researches were carried out in ESL classrooms (Zhang, 2015), only a few researches were done in the EFL context (Gustine, 2013, 2018; Ko, 2010), especially in Indonesia (Huang, 2011). In addition, Ko (2010) found that in some Asian country, the knowledge of critical literacy is still lacking.

Based on the aforementioned explanation above, there is a need to investigate teachers' beliefs and knowledge of critical literacy. This research also discovers teachers' expectations related to how they can develop critical literacy-based classes. In order to achieve these purposes, there are three research questions:

1. What does critical literacy mean for English teachers?

2. How are the English teachers' beliefs about critical literacy as a pedagogical approach?

3. What are the English teachers' expectations in an effort to develop a critical literacy-oriented classroom?

\section{A. Critical Literacy}

The word "critical" is originated from the Greek word Kritikos, it refers to the capability of judging and arguing (Luke \& Woods, 2009), while the term 'literacy' semantically defines as the capability of reading and writing (Kalantzis \& Cope, 2012). In relation to the learning process, it presents the way in how the world can be changed by the process of meaning-making (Freire \& Donaldo, 1987). In this present time, the capability of meanings making is embedded in critical 
literacy, it is facilitated by the use of various modes of texts such as books, television, the internet, popular websites, video, and visual images (Stone \& Schowen, 2010).

In this research, the critical literacy approach in English language education is highly affected by the theory of critical pedagogy stated by (Freire, 1970). Critical pedagogy creates a conscious effort to uncover unbalanced power relations in society through literacy education. Freire (1970) who declared critical pedagogy, encourages a transformation of thinking, as well as teaching and learning. As a result, critical educators are tasked with helping students to become socially aware through reading and writing activities related to their daily lives. With this social awareness, students are expected not to be easily manipulated by others (Freire \& Donaldo, 1987). In line with this, other educators such as McLaren (2003) and Fairclough (2010), continuously increase the role of critical awareness in overcoming social problems in an active and positive way. Furthermore, Janks (2010) and Hood (1998) stated that critical literacy is a philosophy that identifies the relationship between language, power, and knowledge and how language is utilized to support domination. In addition, McLaughlin \& DeVoogd (2004) stated that a critical approach to language learning and literacy also investigates the influence of words and grammatical structures on world representations.

\section{B. The importance of Critical Literacy.}

Critical literacy provides many importance for both teachers and students, especially in developing their social awareness. Critical literacy lends itself to promote action for social justice (Norris, Lucas \& Prudhoe, 2012). It can motivate students to read books and begin discussions on difficult issues of power, race, gender, and class (McLaughlin \& Allen, 2002). In line with this, Park (2012), also Peterson and Chamberlain (2015) found that the implementation of critical literacy could support students to become aware to other people, society, power, culture, and especially the text itself.

Students who engage in critical literacy become openminded, active, strategic readers who are capable of viewing text from a critical perspective (McLaughlin \& Allen, 2002). They will understand that the information presented in texts, magazines, newspapers, song lyrics, and websites has been authored from a particular perspective for a particular purpose (Lewison, Flint \& Van Sluys, 2002). Through implementation of critical literacy, children and teachers can explore and come to understand and appreciate the similarities and differences that they have and share these with each other (Koo, Wong, \& Kemboja, 2012).

Additionally, Zhang (2015) proposed some importance of critical literacy implementation. First, applying critical literacy in teaching and learning practices will help students to get critical access to the context of linguistic, social, cultural, and personal related to the text. Second, applying critical literacy can help students to be able to identify the ideology that shape the author concept. Third, applying critical literacy will help students to think critically and link their understanding with social and power relation. Fourth, applying critical literacy can help students to have a better exposure of the popular information and issues around them.

\section{Critical Literacy in EFL Context}

This section examines a number of important studies relating to the implementation of critical literacy in the EFL context in Indonesia together with several other countries and identifies gaps in specific areas of the EFL Indonesia classroom. Possible reasons for the lack of published research on critical literacy in this field are highlighted.

In Indonesia, the literature relating to critical literacy is limited, especially in English language education and at the university level. Gustine (2013) highlighted critical literacy in the EFL context carried out in Indonesian secondary schools that are lacking in the literature regarding critical pedagogy in Indonesia. Then, Gustine (2018) made a study that was a survey of teacher knowledge of critical literacy and their effort to develop critical-oriented class. It found that the majority of teachers did not have a clear idea on how to create critical classroom, how to assist their students to become critical learners, and what strategies that they have to be employed in providing a critical classroom. The two studies above hope that further research on critical literacy will be carried out with wider coverage.

In wider EFL settings there are a number of critical literacy studies relate to the importance and difficulty of implementing critical literacy in their classrooms at various levels of the school that are relevant to this study. The study conducted by Huang (2011) showed that critical literacy and conventional literacy learning helped students discover the multiple perspectives of an issue and enhanced their reading comprehension through the critical questions that improved their understanding of the article through dissecting and analyzing the content. Moreover, the study conducted by Kaur and Sidhu (2014) and Bacon (2017) showed that critical literacy is difficult to put into practice because it embraces multiple and conflicting perspectives of students.

The lack of research on critical literacy in EFL settings has mostly been linked to lack of teacher confidence in student capacity and teachers' knowledge of critical literacy Gustine (2018). In contrast, this research is expected to enrich the collection of literature on teachers' beliefs and knowledge of critical literacy in EFL context and discovering teachers' expectation in an effort to develop critical literacy-oriented classroom.

\section{METHOD}

In order to investigate teachers' beliefs and knowledge of critical literacy pedagogy in English as a Foreign Language context, I distributed a number of questions in the form of open-ended online questionnaire, followed by an interview. The participants of this study were seventeen English teachers from different schools and level of teaching in Garut, West Java, Indonesia, who have been taught between one to sixteen years.

Related to the three research questions, the questionnaire's questions were developed likewise the purposes of this study. The questions were reviewed by my colleagues, before those were distributed to the participants (Thomas, 2006). The questionnaires were all open-ended and consisted of three main 
parts. The first section was related to the participants' knowledge of critical literacy in general. The second section was the participants' beliefs of the critical literacy as a pedagogical model in English teaching and learning practices. The third was participants' expectation in an effort to develop critical literacy- oriented English classroom.

Apart from the questionnaire, an interview was also conducted with four participants to engage in a topic related to every section in the questionnaire. These four participants volunteered to be interviewed in this study. Further, the interview was recorded and transcribed immediately.

The inductive content analysis was used to analyze the results of questionnaire and interview (Fisher, 2005), data from both the questionnaires and the interview were analyzed to divide it into some emerging themes related to the teachers' knowledge on critical literacy, their beliefs on the use of it, and their expectation in an effort to develop the critical literacyoriented classroom

\section{FINDINGS AND DISCUSSION}

The following section discusses the findings and discussions from the questionnaires and the interview. The findings and discussions are divided into three main issues in accordance with the research questions. The first theme examines the participants' knowledge of critical literacy; the second sub-section investigates English teachers' beliefs of critical literacy; while the last theme explores the teachers' expectation in an effort to develop critical literacy in English classroom.

\section{A. What critical literacy means for English teachers}

The first theme in the questionnaire was related to teachers' understanding of critical literacy from their perspectives and experience as English teachers. Responding to this question, almost all teachers still considered that critical literacy was similar to critical thinking, which only focuses on how a person can read and understand the text as a whole and think it critically. For example, some participants mentioned that critical literacy meant students' ability to read and think critically and be able to differentiate facts from opinions. Some other participants believed that in critical literacy, students are required to investigate the content and validate the information they received to get clarity of information. A number of characteristics of critical literacy that participants stated above, such as the ability to read and think critically, the ability to differentiate facts from opinions, and the ability to critically investigate the validity of information they receive, are literally relevant to critical thinking. In line with this, Van Sluys, Lewison, and Flin (2006) suggested that in doing critical thinking students are committed by those skills mentioned before. However, in critical literacy education, the goal is one step ahead. Students and teachers engaged in critical literacy should begin to think from critical perspectives extensively; for example, when students read something, they have to be able to question whose voice is heard and whose voice is not heard, why this text is written this way and who benefits, how readers and writers are positioned socially in the texts, etc. (Lewison, Flint \& Van Sluys, 2002; Kaur \& Sidhu, 2014).
Apart from the teacher's misunderstanding between critical literacy and critical thinking, another response related to this question is the way the teacher associates critical literacy with reading and writing. Only two of the seventeen participants associate critical literacy with reading and writing. Both participants stated that to be involved in critical literacy, students must have the ability to read and write and understand the full meaning of the text. From these findings, it can be concluded that for some teachers, it still defines that literacy is only limited to reading and writing skills. Meanwhile, in critical literacy education, literacy itself has experienced significant changes from the ability to read and write things that are often related to technical communication skills (Kalantzis \& Cope, 2012), to the learning process where we learn how to create and understand meaning to change world (Freire \& Donaldo, 1987). At this time, the ability to make meaning embedded in critical literacy is facilitated by the use of text in various modes such as from the internet, videogames, images, graphics, and layout (Stone \& Schowen, 2010).

Further, there were three answers from the participants which were almost close to the definition of critical literacy. They define critical literacy as the ability to analyze texts by criticizing obscurity, the author's political views, power, beliefs, and proving it through other relevant sources. They not only view literacy as the ability to read and write, but develop these abilities into things that are deeper and beyond the text itself. Their knowledge of critical literacy is in line with what was conveyed by Riley (2015) and Zhang (2015), they stated that critical literacy is the ability to criticize and analyze texts that question the strength, values, and sounds that are not heard from a text. In addition, most of information related to critical literacy that teachers got were from their discussion in class when they were in university, some of them got the information from the article that they had read.

\section{B. Teachers' beliefs in critical literacy}

Different from the answer to the first question where almost all participants have a less convincing idea of what critical literacy is, in the second question they believe that critical literacy is important and can be implemented as an alternative model in teaching English. They believe that the implementation of critical literacy can encourage students to be more critical because they are required to be able to think beyond what they read; to comprehend the text comprehensively by looking for relevant sources relevant to the text to avoid misunderstanding; to analyze texts in different perspectives to avoid disagreement and become a fair reader; to become the intelligent readers who can prevent themselves from being deceptive, where that capability is needed in today's fast-paced era. Additionally, they believe that critical literacy can be used to teach English, because students learn many kinds of texts in English lesson, and it can be used to teach writing and reading, however, critical literacy can also be used in every lesson at school since the use of text is frequently used. One participant said:

I believe that the implementation of critical literacy will be very beneficial, because it can foster students to be more critical, to understand the texts comprehensively, to analyze 
the texts in different point of view, to be the smart reader that can prevent themselves from hoax information.

Participants' explanations about critical literacy were related to how to understand the meaning beyond the text and become a critical reader. In line with this, some proponents of critical literacy stated that critical literacy is related to criticizing and analyzing the underlying ideology that the author's purposes (Zhang, 2015). Moreover, this answer also supported by McLaughlin \& Allen (2002) who stated that students who engage in critical literacy become open-minded, active, strategic readers who are capable of viewing text from a critical perspective.

Related to teacher statement that critical literacy can also be used in every lesson at school since the use of text is frequently used. Some proponents stated that students' who engage with critical literacy will understand that the information presented in texts, magazines, newspapers, song lyrics, and websites has been authored from a particular perspective for a particular purpose (Lewison, Flint \& Van Sluys, 2002). It is related to the subjects that students learn in schools that demand a lot of use of different modes of texts and teaching and learning media. Therefore, besides English lessons, critical literacy skills are also needed in a variety of subjects at school.

\section{The teachers' expectation in an effort to develop critical literacy-oriented English classroom}

The last question of the questionnaire was to investigate the participants' expectation in an effort to develop critical literacy-oriented English classroom. When discussing some practical recommendations, the teachers seem unsure about how to start. Apart from that, their knowledge of the critical literacy itself and students' English proficiency seemed to be the main concern for the participants in this study. Related to teacher knowledge, they considered that their knowledge of critical literacy was very lack and it might have an impact on the teaching and learning process. In line with this, Gustine (2018) argues that English language teachers still have few knowledges about what critical literacy is and how to apply it in English classes. Whereas, in an effort to apply critical literacy in the classroom, it is teachers who become the starting point for the successful implementation of critical literacy itself, since teachers can help students to become critical readers and provide space for students to develop their critical abilities (McDaniel, 2006). Regarding to students' English proficiency, teachers assume that their classes will tend to be passive because their students might be afraid to argue in English, because they do not know how to produce a good sentence with a good grammar and they have limited vocabulary. As stated by Peterson and Chamberlain (2015) the low ability to speak English becomes a problematic issue in applying critical literacy in the classroom.

Based on the statements above, some expectations were expressed by English teachers who took part in this study. There are three main themes in teacher expectations of the implementation of critical literacy in the classroom: socialization, workshop, and research. In socialization, teachers consider that the socialization of critical literacy is very important, from this activity they expect that they can find out what is critical literacy, why should they implemen critical literacy, and how to implement it in class clearly from the experts. Second is a workshop, in this activity the teachers expect to obtain information about how to prepare lesson plans, student activities, assessments and evaluations based on critical literacy approach. Then the last is research, teachers also expect to be able to obtain information from research on critical literacy especially with settings and participants who are close to them, therefore, they can get a more real picture of the development of critical literacy in their area.

\section{CONCLUSION}

From the results of the open-ended questionnaire and interviews, it can be concluded that most of the teachers in this study might not fully understand the essence of critical literacy in teaching English. However, some participants seemed to have a critical awareness of what and what kind of critical literacy is in the classroom. In addition, participants in this study highly confident in implementing critical literacy to enhance students' ability to criticize and analyze text. Even so, teachers expect that socialization, workshops, and research are still very much needed to develop critical literacy-oriented English classes.

For teachers who want to implement critical literacy, some experts in this field have outlined strategies that can be used in the classroom, especially in the EFL contexts. First, the teachers must first become a critical reader to help students become critical (Riley, 2015). Then, they can apply the fivestep instructional framework which comprises: explaining, demonstrating, guiding, practicing, and reflecting (McLaughlin \& Allen, 2002)

In the first step, teachers must explain what critical literacy is and demonstrate how they can implement the critical literacy in the classroom. After that they can start critical literacy with everyday texts (Lewison, Flint \& Van Sluys, 2002; 34] where they direct students to question something that is considered normal in their environment. Teachers can start with textbooks that are commonly used in schools (Cervetti, Pardales \& Damico, 2001), and then give students the opportunity to identify whose voices are heard and whose voices are missing (Kaur \& Sidhu, 2014). In addition, they may also want to enter various modes of text in the classroom in the form of exercises to provide variations in the classroom so that students exposure to various kinds of text increases. The final step is to reflect on the activities that they have done. These activities can take the form of brief reviews and conclusions or in the form of reflective journals (Gustine, 2013).

Since studies on critical literacy in the EFL pedagogical contexts are relatively scanty, this study is expected to strengthen the knowledge of Indonesian EFL teachers on critical literacy and its implementation in classroom practices. Therefore, for further research, a more comprehensive study involving more teachers in all regions of Indonesia will be very useful. With more time, it is hoped that we can explore this issue more deeply and pay attention to changes and challenges that teachers may experience in their classrooms.

Finally, I want to encourage literacy experts to introduce critical literacy to English teachers. With the changing times, 
technology, social and culture in Indonesia today, students need to be equipped with critical literacy skills. However, without critically literate teachers, this goal may not be fully achieved.

\section{REFERENCES}

Alwasilah, A. C. (2001). Language, culture, and education: A portrait of contemporary Indonesia. Andira.

Bacon, C. K. (2017). Multilanguage, multipurpose: a literature review, synthesis, and framework for critical literacies in English language teaching. Journal of Literacy Research, 1-30. doi: 10.1177/1086296X17718324

Cervetti, G., Pardales, M. J., \& Damico, J. S. (2001). A tale of differences: Comparing the traditions, perspectives, and educational goals of critical reading and critical literacy. ReadingOnline, 4(9), 80-90.

Coffey, H. (2010). Critical literacy. Journal of Adolescent and Adult Literacy, 87.

Emilia, E. (2010). Teaching Writing: Developing Critical Learners. Bandung: Rizqi Press

Fairclough, N. (2010). Critical discourse analysis ( $2^{\text {nd }}$ ed.). London: Routledge.

Fisher, A. (2005). Thinking skills and admission to higher education. A special paper, commissioned by the University of Cambridge Local Examinations Syndicate. and produced by Centre for Research in Critical Thinking, University of East Anglia.

Freire, P. (1970). Pedagogy of the oppressed. London: Penguin Books.

Freire, P., \& Donaldo, M. (1987). Literacy: Reading the word and the world. South Hadley, Mass: Bergin \& Garvey.

Gustine, G. G. (2013). Designing and implementing a critical literacy-based approach in an Indonesian EFL secondary school. International Journal of Indonesian Studies, 1.

Gustine, G. G. (2018). A survey on critical literacy as a pedagogical approach to teaching English in Indonesia. Indonesian Journal of Applied Linguistics, 7(3), 531-537. doi: 10.17509/ijal. v7i3.9798

Hood, S. (1998). Critical literacy: What does it mean in theory and practice. Teachers' voices, 3, 11-19.

Huang, S. (2011). Reading "further and beyond the text": student perspectives of critical literacy in EFL reading and writing. Journal of Adolescent \& Adult Literacy 55(2), 145-154. doi:10.1002/JAAL.00017

Janks, H. (2010). Literacy and power. New York: Routledge.

Kalantzis, M., \& Cope, B. (2012). Literacies. Port Melbourne: Cambridge University Press.

Kaur, S. \& Sidhu, G. K. (2014). Evaluating the critical literacy practices of tertiary students. Procedia-Social and Behavioral Sciences, 123(2014), 44-52. doi:10.1016/j.sbspro.2014.01.1396

Ko, M. Y. B. (2010). Critical literacy development in a college-level English reading class in Taiwan. Indiana University.
Koo, Y.L., Wong, F.F. \& Kemboja Ismail. (2012). Students' critical consciousness through critical literacy awareness. Gema Online ${ }^{\circledR}$ Journal of Language Studies, 12(1), 727-143.

Lee, C. J. (2011). Myths about critical literacy: What teachers need to unlearn. Journal of Language and literacy education, 7(1), 95-102.

Lewison, M., Flint, A. S., \& Van Sluys, K. (2002). Taking on critical literacy: The journey of newcomers and novices. Language arts, 79(5), 382-392.

Luke, A., \& Woods, A. F. (2009). Critical literacies in schools: A primer. Voices from the Middle, 17(2), 9-18.

McDaniel, C. A. (2006). Critical literacy: A way of thinking, a way of life (Vol. 296). Peter Lang.

McLaren, P. (2003). Critical pedagogy: A look at the major concepts. In, A. Darder, M. Baltodano, \& RD Torres (Eds.) The critical pedagogy reader.

McLaughlin, M., \& Allen, M. B. (2002). Guided Comprehension: A Teaching Model for Grades 3-8. Order Department, International Reading Association, 800 Barksdale Road, PO Box 8139, Newark, DE 19714 8139.

McLaughlin, M., \& DeVoogd, G. (2004). Critical literacy as comprehension Expanding reader response. Journal of Adolescent \& Adult Literacy, 48(1), 52-62.

Norris, K., Lucas, L., \& Prudhoe, C. (2012). Examining critical literacy: Preparing preservice teachers to use critical literacy in the early childhood classroom. Multicultural Education, 19(2), 59-62.

Park, J. Y. (2012). A different kind of reading instruction: Using visualizing to bridge reading comprehension and critical literacy. Journal of Adolescent \& Adult Literacy, 55(7), 629-640. doi:10.1002/jaal.00074

Peterson, K. E., \& Chamberlain, K. (2015). "Everybody Treated Him Like He Was From Another World": Bilingual Fourth Graders Develop Social Awareness Through Interactive Read-Alouds Focused on Critical Literacies. Literacy Research and Instruction, 54(3), 231-255. doi:10.1080/19388071.2015.1027020

Riley, K. (2015). Enacting critical literacy in English classrooms: How a teacher learning community supported critical inquiry. Journal of Adolescent \& Adult Literacy, 58(5), 417-425. doi:10.1002/jaal.371

Stone, J. C., \& Schowen, R. A. (2010). Convergence: A framework for a "new" critical literacy. In Multiliteracies and technology enhanced education: Social practice and the global classroom (pp. 35-52). IGI Global.

Thomas, D. R. (2006). A general inductive approach for analyzing qualitative evaluation data. American journal of evaluation, 27(2), 237-246.

Van Sluys, K., Lewison, M., \& Flint, A. S. (2006). Researching critical literacy: A critical study of the analysis of classroom discourses. Journal of Literacy Research, 38(2), 197-233. doi:10.1207/s15548430jlr38024

Wood, K. D., Soares, L., \& Watson, P.(2006). Empowering adolescents through critical literacy. Middle School Journal, 37(3), 55-59. doi:10.1080/00940771.2006.11461537

Zhang, G. (2015). Learning critical literacy in ESL classroom. Creative Education, 6, 1316-1321 